\title{
Fascicle Length of Gastrocnemius Muscles in Monozygous Twins
}

\author{
Takashi Abe \\ Department of Exercise and Sport Science, Tokyo Metropolitan University
}

\begin{abstract}
A large inter-individual variation is seen in muscle fascicle length of the athletes but the reasons for this phenomenon are unclear. The purpose of this study was to determine whether genetic factors contribute to the variances in muscle architectural characteristics. Nine monozygous twin pairs ( 3 males and 6 females), mean age 23 years (range 17-40) were studied. Fascicle length, pennation angle, and muscle thickness of the medial (MG) and lateral (LG) gastrocnemius muscles were measured in vivo by B-mode ultrasound. In the LG muscle intrapair resemblance $(\mathrm{P}<0.01)$ for fascicle length $(\mathrm{r}=0.98)$, pennation angle $(\mathrm{r}=0.94)$ and muscle thickness $(\mathrm{r}=0.86)$ were observed. In MG muscle, however, there was no intrapair resemblance for fascicle length $(\mathrm{r}=0.66$, $\mathrm{P}>0.05)$, although pennation angle $(\mathrm{r}=0.73, \mathrm{P}<0.05)$ and muscle thickness $(\mathrm{r}=0.86, \mathrm{P}<0.01)$ were significant. Mean percent intrapair difference in $\mathrm{LG}$ and $\mathrm{MG}$ muscles were $1.8 \%$ and $5.1 \%$ for fascicle length, $11.3 \%$ and $12.3 \%$ for pennation angle and $12.4 \%$ and $9.9 \%$ for muscle thickness, respectively. There is intrapair difference between muscle thickness and pennation angle in both $\mathrm{MG}(\mathrm{r}=0.69$, $\mathrm{P}<0.05)$ and $\mathrm{LG}(\mathrm{r}=0.70, \mathrm{P}<0.05)$ muscles. However, no significant correlation was observed for intrapair difference between muscle thickness and fascicle length in both muscles (MG, $r=0.46$; $L G, r=0.40$ ). It appears that genetic predisposition is the predominant factor for the determination of muscle fascicle length. However, a lack of intrapair resemblance in MG fascicle length raises the possibility that fascicle length may be further influenced by external environmental factors such as physical training. J Physiol Anthropol 21 (6): 291-295, 2002 http://www.jstage.jst.go.jp/en/
\end{abstract}

Keywords: muscle architecture, pennation angle, muscle thickness, ultrasound

\section{Introduction}

It is well known that the number of sarcomeres in series is proportional to muscle fascicle length and that this factor is important for determining the maximum shortening velocity of muscle (Bodine et al., 1982; Sacks and Roy, 1982; Spector et al., 1980). In athletes, a large inter-individual variation has been observed in muscle fascicle length (Abe et al., 1998, 1999; Kearns et al., 1998, 2000; Kumagai et al., 2000). The absolute and relative fascicle length of selected locomotor muscles is greater in elite sprinters when compared to those obtained in either elite distance runners or untrained subjects (Abe et al., 2000, 2001). Furthermore, a significant correlation exists between 100-m personal-best performance and muscle fascicle length in selected locomotor muscles in 100-m sprint specialists (Abe et al., 2001; Kumagai et al., 2000). However, the reasons for the large inter-individual variation in fascicle length are unclear.

Muscle fascicle length might be determined by genetic and/or environmental factors. A powerful tool for determining the influence of environmental factors independent of any genetic effect is the use of monozygous twin pairs. Any intrapair differences in muscle architecture in genetically identical individuals must be due to differences in environment. Thus, the purpose of this study was to determine whether there was intrapair difference in monozygous twins with respect to muscle architectural characteristics.

\section{Methods}

\section{Subjects}

Written and informed consent to participate in this study was obtained from nine pairs of healthy male $(n=3)$ and female $(n=6)$ monozygous twins (Table 1$)$, mean age 23 years (range 17-40 years). Three pairs of twins (Case A twins), each had one twin who was physically active (soccer, tennis and track \& field), and participated at the local and/or national level of competition, while their corresponding sibling was not active. In the other 6 pairs of twins, neither twin had a history of physical activity. The monozygosity of the twins was established on the 
Table 1 Physical characteristics of female and male monozygous twins

\begin{tabular}{|c|c|c|c|c|c|c|c|c|}
\hline & \multirow{2}{*}{ Sex } & \multirow{2}{*}{ Age (yr) } & \multicolumn{2}{|c|}{ Height (cm) } & \multicolumn{2}{|c|}{ Weight (kg) } & \multicolumn{2}{|c|}{ Calf girth (cm) } \\
\hline & & & A & B & A & B & A & B \\
\hline Twin $1^{\dagger}$ & $\mathrm{F}$ & 17 & 152.7 & 155.7 & 39.6 & 46.8 & 29.8 & 34.0 \\
\hline Twin $2^{\dagger}$ & $\mathrm{F}$ & 17 & 158.3 & 158.0 & 83.5 & 67.0 & 44.0 & 38.2 \\
\hline Twin 3 & $\mathrm{~F}$ & 17 & 157.6 & 158.0 & 41.0 & 39.0 & 30.2 & 29.5 \\
\hline Twin 4 & $\mathrm{~F}$ & 18 & 157.8 & 157.4 & 47.0 & 46.7 & 31.5 & 30.6 \\
\hline Twin 5 & $\mathrm{~F}$ & 25 & 153.5 & 150.7 & 44.1 & 43.3 & 31.4 & 31.6 \\
\hline Twin $6^{\pi}$ & $\mathrm{F}$ & 40 & 157.1 & 157.3 & 53.1 & 53.5 & 36.8 & 38.2 \\
\hline Twin 7 & M & 19 & 162.7 & 164.8 & 50.5 & 50.7 & 35.9 & 34.7 \\
\hline Twin $8^{\pi}$ & M & 30 & 166.7 & 166.1 & 61.3 & 67.3 & 37.5 & 38.4 \\
\hline Twin $9^{\mathbb{\pi}}$ & M & 30 & 161.7 & 161.9 & 54.3 & 52.6 & 34.8 & 34.8 \\
\hline
\end{tabular}

" Case A twins, ${ }^{\dagger}$ Case B twins.
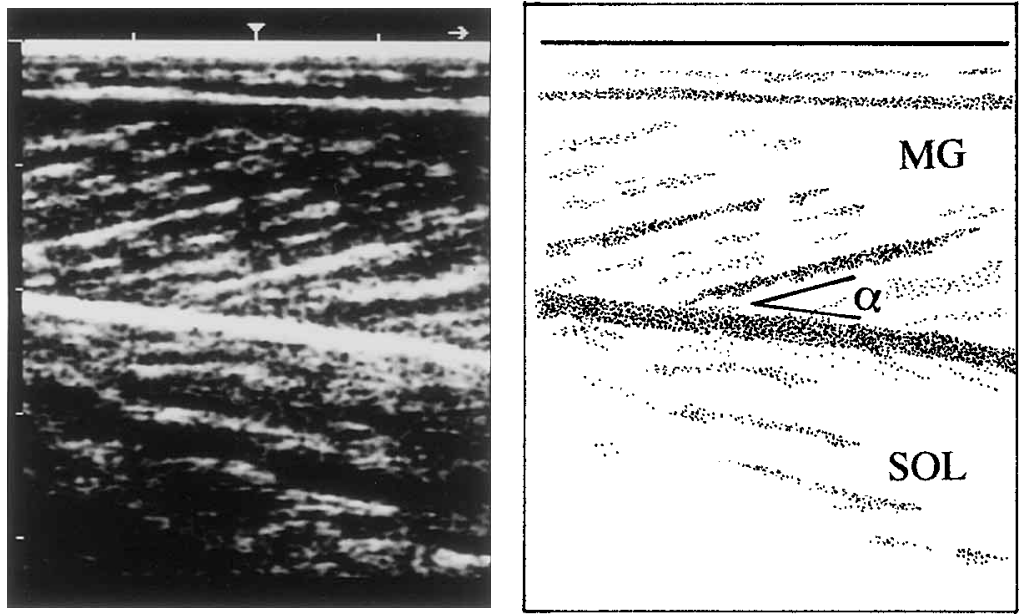

\section{AT-M interface}

I-M interface

(APN)

Fig. 1 Ultrasonic images representing the gastrocnemius medialis (MG) and soleus (SOL) muscles. White lines in the longitudinal image indicate echoes from the deep aponeurosis (APN) and the interspace between fascicles. (AT-M subcutaneous adipose tissue-muscle, I-M intermuscular, $\alpha$ fascicle pennation angle).

basis of a questionnaire, physical appearance, the similarity of several red blood cell antigens, and the A, B, and $\mathrm{C}$ loci of the HLA-antigen system.

\section{Skeletal muscle architecture}

The longitudinal ultrasonic images of the medial (MG) and lateral (LG) gastrocnemius muscles were obtained at $30 \%$ proximal level of lower leg (the distance between the lateral malleolus of the fibula and the lateral condyle of the tibia), using the B-mode ultrasound apparatus (Aloka SSD-500, Tokyo, Japan). Briefly, the measurements were carried out while the subjects stood with their weight evenly distributed between both legs. The mediolateral widths of the MG and LG muscles were determined by ultrasound over the skin surface, and the position of onehalf of the width was used as a measurement site. The echoes from interspaces of fascicles and from the superficial and deep aponeurosis were visualized (Kawakami et al., 1998; Kumagai et al., 2000), and the ultrasonic images were printed onto calibrated recording film (UPP-110HA, Sony, Tokyo). From the printed images, the distance from the adipose tissue-muscle interface and intermuscular interface was accepted as muscle thickness. The fascicle pennation angle was measured from the angles between the echo of the deep aponeurosis of each muscle and interspaces among the fascicles of that muscle (Figure 1). The length of fascicles across the deep and superficial aponeurosis was measured as a straight line (Abe et al., 1998, 2000). In each muscle the average of the five images was used for data analysis. The estimated coefficient of variation of this fascicle length determination is $3.7 \%$.

\section{Statistical analysis}

The intraclass correlation coefficient which quantifies the intrapair resemblance was obtained using a Pearson product moment. The correlation for absolute intrapair differences was computed among the muscle architectural 

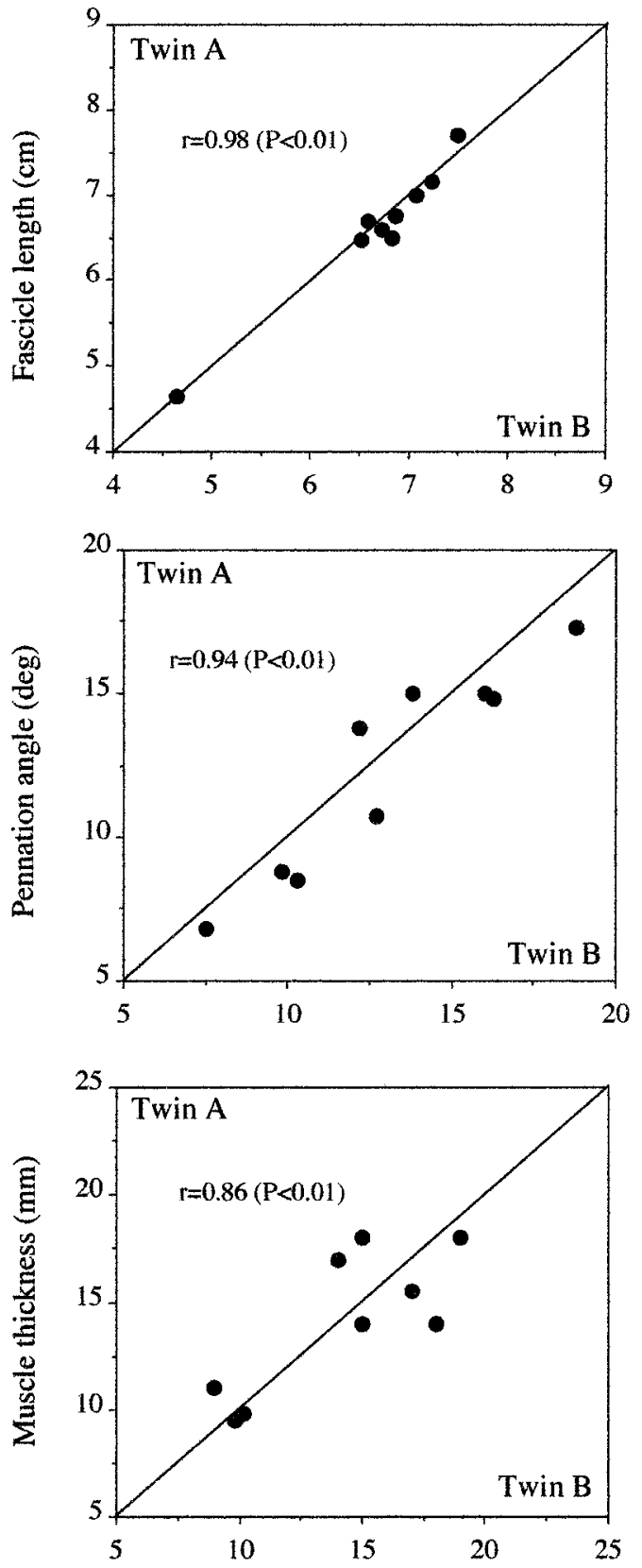

Fig. 2 Intrapair correlation coefficients for muscle architectural parameters in the lateral gastrocnemius (LG) muscle.

parameters. In each statistical analysis the level of significance was set at $\mathrm{P}<0.05$.

\section{Results}

In the LG muscle (Figure 2), there were intrapair resemblance for fascicle length $(\mathrm{r}=0.98, \mathrm{P}<0.01)$, pennation angle $(\mathrm{r}=0.94, \mathrm{P}<0.01)$ and muscle thickness $(\mathrm{r}=0.79, \mathrm{P}<0.05)$. In MG muscle (Figure 3), however, no intrapair resemblance for fascicle length $(r=0.66, P>0.05)$ was observed, although pennation angle $(\mathrm{r}=0.73, \mathrm{P}<0.05)$
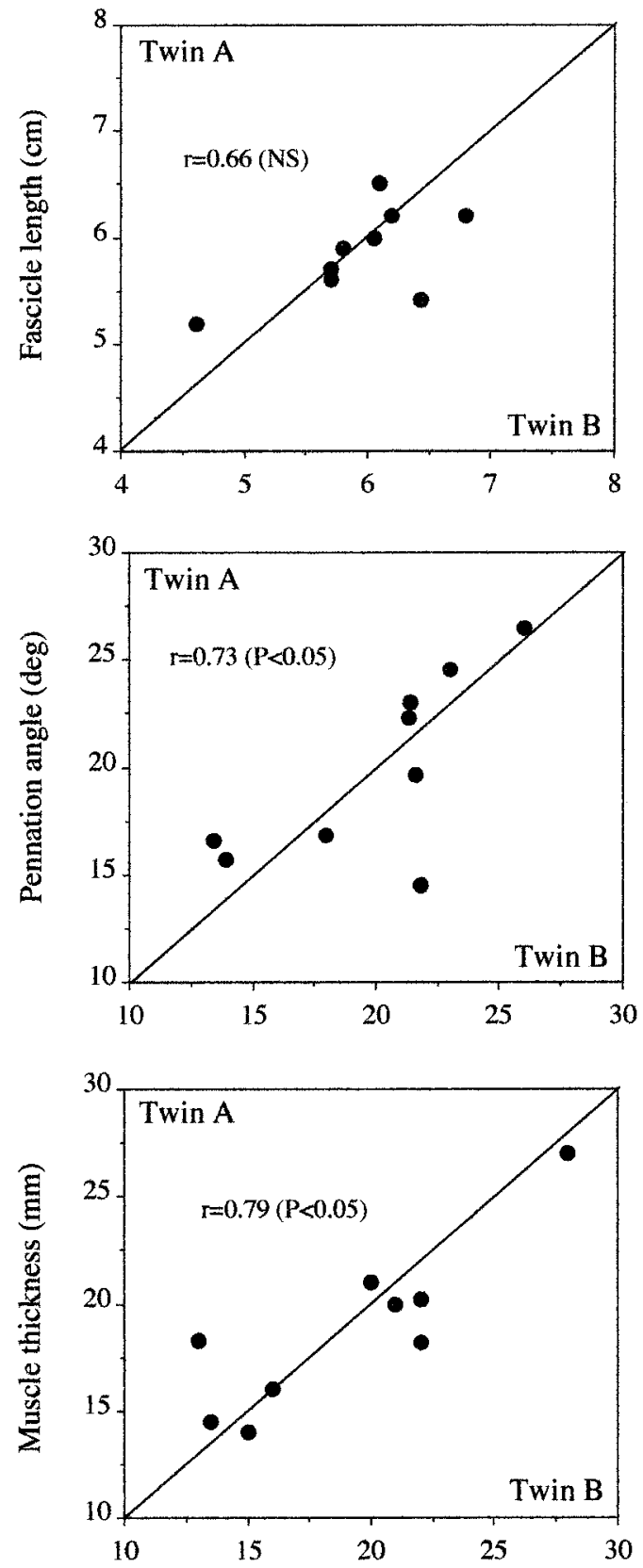

Fig. 3 Intrapair correlation coefficients for muscle architectural parameters in the medial gastrocnemius (MG) muscle.

and muscle thickness $(\mathrm{r}=0.86, \mathrm{P}<0.01)$ were significant.

The average percent intrapair differences in fascicle length, pennation angle and muscle thickness were 5.1\%, $12.3 \%$ and $9.9 \%$ for $\mathrm{MG}$ and $1.8 \%, 11.3 \%$ and $12.4 \%$ for LG, respectively. A correlation was observed for intrapair difference between muscle thickness and pennation angle in both $\mathrm{LG}(\mathrm{r}=0.70, \mathrm{P}<0.05)$ and $\mathrm{MG}(\mathrm{r}=0.69, \mathrm{P}<0.05)$ muscles. However, there were no correlations $(\mathrm{P}>0.05)$ for intrapair difference between muscle thickness and fascicle length in both $\mathrm{LG}(\mathrm{r}=0.40)$ and $\mathrm{MG}(\mathrm{r}=0.46)$ muscles. 


\section{Discussion}

This study was designed to explore the reasons for the large inter-individual variation in skeletal muscle architecture of the athletes. The major finding of the present study demonstrated that there was no significant intrapair resemblance in MG fascicle length. This finding would support the concept that fascicle length can be modified by environmental factors. However, a high intrapair resemblance was found for all of the other muscle architectural parameters (pennation angle and muscle thickness). In addition, the correlation for intrapair difference between muscle size (muscle thickness) and fascicle length was not significant. The lack of a significant correlation between these variables would tend to argue against the possibility of environmentallyinduced fascicle lengthening. Take together, these data appear contradictory, but a closer examination might appear to suggest a time-course explanation for fascicle lengthening (Kearns et al., 2000) as follows. In three pairs of twins (Case A twins), in which one twin trained and the other did not, there was a large intrapair difference (average 12\%) in MG fascicle length, including the largest twin difference of $19 \%$, compared with that of the other 6 untrained twins pairs (average 2\%). Within the two pairs (Case B twins) of the 6 untrained twin pairs, on the other hand, one individual twin in each pair possessed greater body weight and larger MG muscle thickness than their corresponding siblings. In these Case B twins, MG fascicle length was similar within pair, while pennation angle was greater in the heavier sibling. Theoretically (Maxwell et al., 1974), fiber hypertrophy-induced increments in pennation angle increase tension on the muscle tendon (Brechue and Abe, 2002; Kawakami et al., 1993). Muscle (fiber) enlargement magnifies this tension until a critical pennation angle is reached (Case $B$ twins). The normalizing force from the tendon acts as a stretching force on the fascicles, inducing growth. As the fascicle increases in length, pennation angle decreases (Case A twins), thereby relieving the tension on the fascicles from the tendon. The concept of the critical pennation angle and fascicle tension paradigm (Kearns et al., 2000) may be explanatory for the results of the present study. In addition, a recently published study in junior soccer players demonstrated that a difference in muscle size between the dominant and non-dominant legs is associated with longer fascicle lengths in the dominant leg (Kearns et al., 2001).

Muscle fiber (fascicle) length has been shown to change in animal models following stretch-overload or treadmill downhill running (Ashmore and Summers, 1981; Lynn et al., 1988). The mechanisms believed to result in an increase in fascicle length are either the addition of sarcomeres in series or an increase in sarcomere length. For example, Lynn and co-workers (1988) demonstrated an $8 \%$ increase in sarcomere number and a 5\% difference in fiber length of the rat vastus intermedialis muscle after training by treadmill running on a decline. However, such changes have yet to be demonstrated in humans.

Previous studies (Huijing, 1985; Kawakami et al., 1998; Wickiewicz et al., 1993) have reported that differences in maximum force and maximum shortening velocity between the MG and LG muscles are principally determined by their architectural properties. These differences most likely reflect differences in functional recruitment within the gastrocnemius muscles. Given that fiber type composition is similar between the MG and LG muscles (Johnson et al., 1973), the longer fascicle length in the LG distinguishes it for greater potential shortening velocity. On the other hand, the MG is characterized by shorter fascicle length and larger pennation angle than other triceps surae muscles (Kawakami et al., 1998); this means the MG can pack more fibers within a given volume; distinguishing it for force generation. In the present study, a strong interpair resemblance for fascicle length was found in LG muscle but not in MG muscle. The reasons for the differences between the adaptation in the fascicle length of the MG and LG are unclear, but our result suggested that the MG muscle is more likely to be influenced than LG muscle, as may be demonstrated by its difference in functional recruitment. Clearly, additional studies are necessary to fully understand the possibility and role of muscle fascicle lengthening as an environmental adaptation.

In conclusion, it appears that genetic predisposition is the predominant factor for the determination of muscle fascicle length. However, data exists regarding the $\mathrm{MG}$ fascicle length that raises the possibility that fascicle length may be further influenced by external environmental factors such as physical training.

Acknowledgements I would like to extend my appreciation to the twin pairs who participated in this study. This study was supported by a Grant-in-Aid for Scientific Research (Grant \#11680043) from the Ministry of Education, Science, Sports and Culture, Japan.

\section{References}

Abe T, Brechue WF, Fujita S, Brown JB (1998) Gender differences in FFM accumulation and architectural characteristics of muscle. Med Sci Sports Exerc 30: 1066-1070

Abe T, Brown JB, Brechue WF (1999) Architectural characteristic of skeletal muscle in black and white college football players. Med Sci Sports Exerc 31: 14481452

Abe T, Kumagai K, Brechue WF (2000) Fascicle length of leg muscle is greater in sprinters than distance runners. Med Sci Sports Exerc 32: 1125-1129 
Abe T, Fukashiro S, Harada Y, Kawamoto K (2001) Relationship between sprint performance and muscle fascicle length in female sprinters. J Physiol Anthropol 20: 141-147

Ashmore CR, Summers PJ (1981) Stretch-induced growth in chicken wing muscles: myofibrillar proliferation. Am J Physiol 51: C93-C97

Bodine SC, Roy RR, Meadows DA, Zernicke RF, Sacks RD, Fournier M, Edgerton VR (1982) Architectural, histochemical, and contractile characteristics of a unique biarticular muscle: the cat semitendinosus. J Neurophysiol 48: 192-201

Brechue WF, Abe T (2002) The role of FFM accumulation and skeletal muscle architecture in powerlifting performance. Eur J Appl Physiol 86: 327-336

Huijing PA (1985) Architecture of the human gastrocnemius muscle and some functional consequences. Acta Anat (Basel) 123: 101-107

Johnson MA, Polgar J, Weightman D, Appleton D (1973) Data on the distribution of fiber types in thirty-six human muscles: an autopsy study. J Neurol Sci 18: 111129

Kawakami Y, Abe T, Fukunaga T (1993) Muscle-fiber pennation angles are greater in hypertrophied than in normal muscles. J Appl Physiol 74: 2740-2744

Kawakami Y, Ichinose Y, Fukunaga T (1998) Architectural and functional features of human triceps surae muscles during contraction. J Appl Physiol 85: 398-404

Kearns CF, Abe T, Brechue WF (2000) Muscle enlargement in Sumo wrestlers increased muscle fascicle length. Eur J Appl Physiol 83: 289-296

Kearns CF, Isokawa M, Abe T (2001) Architectural characteristics of dominant leg muscles in junior soccer players. Eur J Appl Physiol 85: 240-243

Kumagai K, Abe T, Brechue WF, Ryushi T, Takano S, Mizuno M (2000) Sprint performance is related to muscle fascicle length in male 100-m sprinters. J Appl Physiol 88: 811-816

Lynn R, Talbot JA, Morgan DL (1988) Differences in rat skeletal muscle after incline and decline running. J Appl Physiol 85: 98-104

Maxwell LC, Faulkner JA, Hyatt GJ (1974) Estimation of number of fibers in guinea pig skeletal muscles. J Appl Physiol 37: 259-264

Sacks RD, Roy RR (1982) Architecture of the hind limb of muscle of cats: functional significance. J Morphol 173: 185-195

Spector SA, Gardiner PF, Zernicke RF, Roy RR, Edgerton VR (1980) Muscle architecture and the force velocity characteristics of the cat soleus and medial gastrocnemius: Implications for motor control. J Neurophysiol 44: 951-960

Wickiewicz TL, Roy RR, Powell PL, Perrine JJ, Edgerton VR (1983) Muscle architecture of the human lower limb. Clin Orthop 179: 275-283

Received: June 25, 2002

Accepted: September 11, 2002

Current Address for Correspondence: Takashi Abe, Ph.D. Department of Exercise and Sport Science, Tokyo Metropolitan University

1-1 Minami-ohsawa, Hachioji, Tokyo 192-0397, Japan

Tel: 0426-77-2968

Fax: 0426-77-2961

e-mail: abebe@comp.metro-u.ac.jp 